\title{
Adenosine Monophosphate-Activated Protein Kinase: A Central Regulator of Metabolism with Roles in Diabetes, Cancer, and Viral Infection
}

\author{
D.G. HARDIE \\ Division of Cell Signalling and Immunology, College of Life Sciences, University of Dundee, \\ Dundee DD1 5EH, United Kingdom \\ Correspondence:d.g.hardie@dundee.ac.uk
}

\begin{abstract}
Adenosine monophosphate-activated protein kinase (AMPK) is a cellular energy sensor activated by metabolic stresses that inhibit catabolic ATP production or accelerate ATP consumption. Once activated, AMPK switches on catabolic pathways, generating ATP, while inhibiting cell growth and proliferation, thus promoting energy homeostasis. AMPK is activated by the antidiabetic drug metformin, and by many natural products including "nutraceuticals" and compounds used in traditional medicines. Most of these xenobiotics activate AMPK by inhibiting mitochondrial ATP production. AMPK activation by metabolic stress requires the upstream kinase, LKB1, whose tumor suppressor effects may be largely mediated by AMPK. However, many tumor cells appear to have developed mechanisms to reduce AMPK activation and thus escape its growthrestraining effects. A similar phenomenon occurs during viral infection. If we can establish how down-regulation occurs in tumors and virus-infected cells, there may be therapeutic avenues to reverse these effects.
\end{abstract}

Adenosine monophosphate (AMP)-activated protein kinase is a protein kinase originally discovered via its ability to inactivate two key enzymes of lipid biosynthesis, that is, acetyl-CoA carboxylase (Carlson and Kim 1973) and 3-hydroxy-3-methylglutaryl (HMG)-CoA reductase (Beg et al. 1973). Both activities were shown to be allosterically activated by AMP (Yeh et al. 1980; Ferrer et al. 1985), but it was not realized that they were catalyzed by the same protein kinase until the author's laboratory provided evidence for this (Carling et al. 1987). Since it soon became clear that this protein kinase had multiple downstream targets, it was renamed the AMP-activated protein kinase (AMPK) (Munday et al. 1988; Hardie et al. 1989).

AMPK exists as heterotrimeric complexes comprising a catalytic $\alpha$ subunit and regulatory $\beta$ and $\gamma$ subunits. In mammals, each subunit occurs as multiple isoforms encoded by multiple genes $(\alpha 1 / \alpha 2 ; \beta 1 / \beta 2 ; \gamma 1 / \gamma 2 / \gamma 3)$, which assemble to form up to 12 heterotrimeric combinations (Hardie 2007), with splice variants further increasing the diversity. From the early studies of HMG-CoA reductase kinase, it was realized that the kinase was activated by phosphorylation by upstream kinases (Ingebritsen et al. 1978). The manner in which this interfaces with effects of adenine nucleotides, allowing the kinase to act as an energy sensor, is discussed below.

\section{ROLE OF AMPK ORTHOLOGS IN NONMAMMALIAN EUKARYOTES}

Orthologs of AMPK genes/subunits occur in essentially all eukaryotes; those in budding yeast (Saccharomyces cerevisiae) had been studied for several years before it was realized that they were related to AMPK. The S. cerevisiae kinase is also a heterotrimeric complex (referred to here as the SNF1 complex) with the $\alpha$ subunit encoded by $S N F 1$, the $\beta$ subunit by three alternate genes (SIP1, SIP2, GAL83) and the $\gamma$ subunit by SNF4 (Hardie et al. 1998). All are required for growth of budding yeast on carbon sources other than glucose, although any one of the three $\beta$ subunit genes is sufficient (Schmidt and McCartney 2000). Nonglucose carbon sources whose utilization requires a functional SNF1 complex include fermentable sugars such as sucrose, maltose, and galactose, and nonfermentable sources such as glycerol and ethanol. In yeast grown solely on glucose, the Snfl complex is required for the diauxic shift that occurs as glucose runs low. During this shift, growth slows and there is a switch from fermentative to oxidative metabolism to generate ATP (Hedbacker and Carlson 2008). Diploid strains also undergo meiosis and sporulation in response to glucose starvation, and this also requires a functional SNF1 complex (Honigberg and Lee 1998).

AMPK orthologs are also found in plants (Alderson et al. 1991; Mackintosh et al. 1992). Deletion of the two catalytic subunit genes in a primitive plant, the moss Physcomitrella patens, produced no phenotype when the plants were grown in continuous light, but the plants failed to grow on more physiological alternate light/dark cycles (Thelander et al. 2004). Since darkness is the equivalent of starvation for a photosynthetic organism, and the yeast ortholog is required during glucose starvation, this suggested that the ancestral role of AMPK was in response to starvation for the key carbon source. Consistent with this, overexpression of the catalytic subunit in 
Arabidopsis thaliana caused resistance to carbohydrate starvation in low light levels, whereas down-regulation of the catalytic subunits resulted in a stunted growth, associated with a failure to execute the transcriptional switch and mobilization of stored starch that normally occur during a dark period. However, in this organism the growth phenotype was not rescued by continuous illumination (Baena-Gonzalez et al. 2007).

In the nematode worm Caenorhabditis elegans, starvation and other stresses in early life result in an extension of life span, but this did not occur when one of the two AMPK catalytic subunits (AAK-2) was knocked out (Apfeld et al. 2004). AAK-2 is required for life-span extension in response to treatment with the plant product resveratrol, and to some but not all protocols of dietary restriction (Greer et al. 2007; Greer and Brunet 2009). It is also required for the arrest of germ cell development that occurs on dietary restriction (Narbonne and Roy 2006), and for inhibition of triglyceride breakdown when worms enter the long-lived Dauer larval form (Narbonne and Roy 2009). Thus, C. elegans AMPK is involved in coupling the availability of nutrients to development and sexual maturation.

\section{MAMMALIAN AMPK-STRUCTURE AND REGULATION}

The functional domains within the $\alpha, \beta$, and $\gamma$ subunits of AMPK are illustrated in Figure 1. The $\alpha$ subunit contains the kinase domain, with the conserved threonine residue that is the target for upstream kinases (Thr172 in human $\alpha 1$ ) located within the activation loop. Phosphorylation at Thr172 is required for kinase activity and function in all species from yeast to man, and with the human kinase causes $>100$-fold activation (Estruch et al. 1992; Hawley et al. 1996; Stein et al. 2000). The upstream kinases that phosphorylate this site were initially identified in S. cerevisiae (Hong et al. 2003; Sutherland et al. 2003), leading to the subsequent identification of LKB1 as the major upstream kinase in mammalian cells (Hawley et al. 2003; Woods et al. 2003). LKB1 had been previously identified (Hemminki et al. 1998) as a tumor suppressor mutated in Peutz-Jeghers syndrome, an inherited susceptibility to cancer in humans. The LKB1 gene is also mutated in many spontaneous, noninherited cancers (Sanchez-Cespedes et al. 2002; Wingo et al. 2009). The discovery that LKB1 was upstream of AMPK introduced for the first time a link between AMPK and cancer. It remains uncertain whether the tumor suppressor effects of LKB1 are entirely mediated by AMPK because, in addition to the two catalytic subunit isoforms of AMPK, LKB1 also activates 12 AMPKrelated kinases (whose functions are less well understood than those of AMPK) via phosphorylation of the residues equivalent to Thr172 (Lizcano et al. 2004). LKB1 is only active when present as a heterotrimeric complex with two accessory subunits, STRAD and MO25 (Hawley et al. 2003), but there is currently little evidence that it is regulated. It appears to phosphorylate AMPK constitutively,
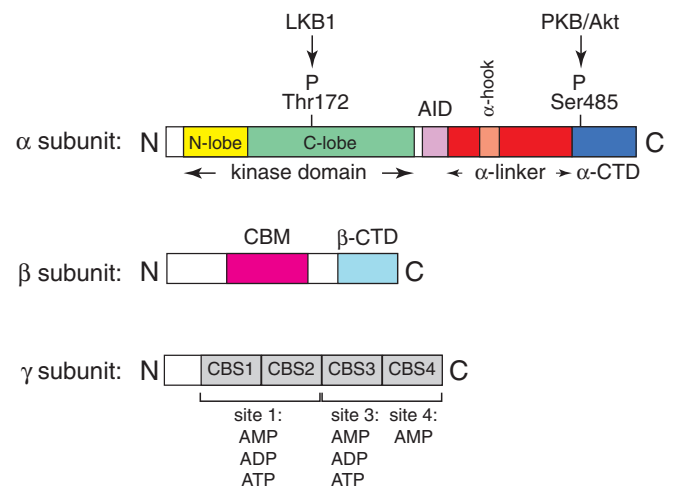

Figure 1. Domain structure of typical $\alpha, \beta$, and $\gamma$ subunits of the adenosine monophosphate-activated protein kinase (AMPK) complex, drawn approximately to scale. The color coding of domains is related to that used in Figure 3 . The catalytic $\alpha$ subunits contain the kinase domain at the amino terminus with the activating phosphorylation site (Thr172 in human $\alpha 1$ ) within the activation loop in the carboxy-terminal lobe. This is followed by the auto-inhibitory domain (AID). The " $\alpha$ linker" connects the kinase domain and the carboxy-terminal domain and has an extended conformation. The " $\alpha$ hook" region of this linker interacts with AMP or ADP bound at site 3 (Fig. 3; Xiao et al. 2011). Phosphorylation of a serine that lies within a flexible loop within the $\alpha$-carboxy-terminal domain ( $\alpha$-CTD; Ser485 in human $\alpha 1$ ) appears to inhibit phosphorylation at Thr172 (Horman et al. 2006). The $\beta$ subunit contains a central carbohydrate-binding module (CBM) and a $\beta$-CTD that forms the core of the $\alpha \beta \gamma$ complex. The $\gamma$ subunit contains an amino-terminal region that interacts with the $\beta-C T D$, and four tandem CBS repeats (CBS1-CBS4). These form two Bateman domains (CBS1: CBS2 and CBS3:CBS4) that provide three binding sites $(1,3$, and 4) for adenine nucleotides.

and the effects of adenine nucleotides on phosphorylation of Thr172 are mediated by binding to AMPK, and not to LKB1 (see below).

Almost as soon as LKB1 was identified as a kinase phosphorylating Thr172, it was realized that there must be others, as some Thr172 phosphorylation was evident even in cells lacking LKB1. The best characterized of these are the $\mathrm{Ca}^{2+}$-activated, calmodulin-dependent kinase kinases (especially CaMKK $\beta$ ), which also act as upstream kinases for the calmodulin-dependent kinases, CaMKI and CaMKIV (Hawley et al. 2005; Hurley et al. 2005; Woods et al. 2005). These cause AMPK activation (in an AMP-independent manner) in response to increases in intracellular $\mathrm{Ca}^{2+}$, and this mechanism is responsible for AMPK activation in response to depolarization of neurones (Hawley et al. 2005), thrombin in endothelial cells (Stahmann et al. 2006), and stimulation of the $\mathrm{T}$ cell receptor in $\mathrm{T}$ cells (Tamas et al. 2006). Unlike LKB1, the CaMKKs do not appear to phosphorylate and activate any of the AMPK-related kinases (Fogarty et al. 2010).

The amino-terminal kinase domain on the $\alpha$ subunit of AMPK is immediately followed (Fig. 1) by the "autoinhibitory domain," so called because truncated constructs containing this domain plus the kinase domain are much less active that those containing the kinase domain alone (Goransson et al. 2007; Pang et al. 2007). 
The auto-inhibitory domain (AID) shows weak sequence similarity to the ubiquitin-associated (UBA)-like domains found in the same location in several of the AMPK-related kinases. A structure of a carboxy-terminally truncated $\alpha$ subunit of the Schizosaccharomyces pombe AMPK ortholog revealed that the AID forms a bundle of three $\alpha$ helices that interacts with the large and small lobes of the kinase domain on the opposite side to the active site (Chen et al. 2009). It was proposed that the AID is involved in the mechanism by which AMP causes allosteric activation, because mutations predicted to disrupt the interaction between the kinase domain and the AID (in the context of the mammalian heterotrimer) increased the basal activity and abolished AMP activation.

The carboxy-terminal domain of the $\alpha$ subunit forms a compact globular domain required for formation of the heterotrimeric complex (Crute et al. 1998). The carboxyterminal domain (CTD) of the $\beta$ subunit wraps around this $\alpha$-CTD and then terminates with two antiparallel strands. These form a $\beta$ sheet with a third strand provided by the amino terminus of the $\gamma$ subunit; this $\beta$ sheet forms the conserved "core" of the $\alpha \beta \gamma$ complex in $S$. cerevisiae, $S$. pombe, and mammals (Amodeo et al. 2007; Townley and Shapiro 2007; Xiao et al. 2007). Nearer to the center of the $\beta$ subunit (Fig. 1) is a conserved domain that is a member of the "CBM20" family of carbohydrate-binding modules (CBMs) (Machovic and Janecek 2006). CBMs are most commonly found (in both prokaryotes and eukaryotes) in enzymes that metabolize starch, glycogen, and related polysaccharides, where their function appears to be to localize the associated catalytic domain on the polysaccharide substrate. The CBM in the AMPK- $\beta$ subunit causes the complex to associate with glycogen particles in intact cells (Hudson et al. 2003; Polekhina et al. 2003), and AMPK also associates with the surface of glycogen particles in vivo (Bendayan et al. 2009). The function of this association remains uncertain, although AMPK does phosphorylate two proteins that are targeted to glycogen, that is (1) muscle glycogen synthase (mGS), whose phosphorylation at site 2 causes inactivation (Carling and Hardie 1989; Jorgensen et al. 2004), and (2) R5/PTG, which targets the catalytic subunit of protein phosphatase-1 (PP1) to glycogen (Vernia et al. 2009). Phosphorylation of R5 is proposed to promote its ubiquitylation and degradation, so that phosphorylation of mGS and R5 by AMPK would not only cause inactivation of $\mathrm{mGS}$, but also dissociation from glycogen of the protein phosphatase (PP1) that reactivates it, the two effects cooperating to inhibit glycogen synthesis. We have shown that certain preparations of glycogen, and also synthetic oligosaccharides based on glycogen, can inhibit AMPK (McBride et al. 2009). Our current hypothesis is that degradation of glycogen (e.g., during exercise in muscle) leads to changes in structure that cause increasing inhibition of the bound AMPK. By inhibiting phosphorylation of $\mathrm{mGS}$ and $\mathrm{R} 5 / \mathrm{PTG}$, this would lead to net dephosphorylation and activation of $\mathrm{mGS}$, thus ensuring that glycogen is rapidly replenished whenever it becomes depleted. This would help to explain the paradox that mGS is found to be dephosphorylated and activated following exercise (Aschenbach et al. 2001), despite the fact that AMPK (which phosphorylates and inactivates mGS) is switched on during exercise (Winder and Hardie 1996). Our model suggests that the pool of AMPK bound to glycogen is regulated by the structural state of glycogen particles, a mechanism not available to other pools of AMPK.

How do AMP and other adenine nucleotides regulate mammalian AMPK? Following the initial observations that AMP allosterically activates AMPK (Yeh et al. 1980; Ferrer et al. 1985), my laboratory showed that AMP also promoted net phosphorylation of Thr172, and hence activation, by a second mechanism (Moore et al. 1991). We subsequently reported that AMP both promoted phosphorylation (Hawley et al. 1995) and inhibited dephosphorylation (Davies et al. 1995), so that (combined with the allosteric effect) AMP activates AMPK by a three-pronged mechanism. When highly purified preparations of bacterially expressed AMPK became available, the effect of AMP on dephosphorylation was confirmed, but the effect on phosphorylation by LKB1 was not (Suter et al. 2006). It was proposed that the apparent effect on phosphorylation of Thr172 may have been an artifact caused by contamination of the kinase preparations used with protein phosphatases (Sanders et al. 2007). However, more recently it has been shown that the lack of effect of AMP on phosphorylation of bacterially expressed AMPK by LKB1 may have been due to the fact that, unlike the native complex, it was not myristoylated at the amino terminus of the $\beta$ subunit (Oakhill et al. 2010).

Studies using a photoaffinity analog of AMP identified the $\gamma$ subunit as the likely location of the adenine nucleotide-binding sites (Cheung et al. 2000). Additional clues came from observations that dominant mutations in the gene encoding the human $\gamma 2$ isoform (expressed at high levels in cardiac muscle), which were associated with a heart disease characterized by premature excitation of the large chambers (Blair et al. 2001; Gollob et al. 2001), were shown to interfere with binding of, and activation by, AMP (Daniel and Carling 2002; Adams et al. 2004; Scott et al. 2004). The $\gamma$ subunits in all AMPK orthologs contain four tandem repeats of a sequence known as a CBS repeat, so called because they are also found in the enzyme cystathionine $\beta$-synthase (Bateman 1997). CBS repeats occur in around 20 proteins in the human genome, although in most cases there are only two tandem repeats, rather than four. Two repeats form a domain (termed a Bateman domain; Kemp 2004) that binds regulatory ligands containing adenosine, usually AMP, ADP, or ATP but, in one case (cystathionine $\beta$-synthase), $S$-adenosylmethionine (Scott et al. 2004).

The structures of the core AMPK complexes from $S$. cerevisiae, $S$. pombe, and mammals show that the two Bateman domains formed by CBS1:CBS2 and CBS3:CBS4 assemble head to head to form a flattened disk with one CBS repeat in each quadrant (Amodeo et al. 2007; Townley and Shapiro 2007; Xiao et al. 2007). This symmetrical arrangement creates four clefts 
near the center where AMP, ADP, or ATP (referred to below as AXP) might bind, two accessible from one side of the disk and two from the other. However, in mammalian AMPK only three are occupied, with the fourth being vacant, possibly because aspartate side chains that interact with ribose hydroxyls of AXPs in the other three sites are not conserved. Although each molecule of bound AXP interacts with side chains from more than one CBS repeat, a useful convention (Kemp et al. 2007) is to number the sites according to the CBS repeat bearing the aspartate residue interacting with the ribose ring. Recent binding studies have helped to define the functions of the three sites (Xiao et al. 2011). Site 1 binds all three AXPs with similar high affinities and, based on the concentrations of AMP that cause allosteric activation, binding at this site appears to be responsible for this effect, which is only observed with AMP (Carling et al. 1989; Xiao et al. 2011). Site 2 is the empty site, whereas site 3 again binds all three AXPs with similar affinities, although their affinities are about 50-fold lower than at site 1 . Site 3 appears to be the site at which AMP binding inhibits dephosphorylation of Thr172, and it has recently been shown that binding of ADP (but not ATP) has the same effect (Xiao et al. 2011). ADP binding at site 3 also appears to promote phosphorylation of Thr172 by upstream kinases (Oakhill et al. 2011). Site 4 , whose function remains unclear, binds AMP very tightly; AMP is already present in this site when recombinant AMPK is purified from E. coli, and it does not exchange with ADP or ATP (Xiao et al. 2007).

The recent findings (Oakhill et al. 2011; Xiao et al. 2011 ) that binding of ADP (as well as AMP) at site 3 promotes net phosphorylation of Thr172 seem likely to be important under physiological circumstances. Because of the action of the mitochondrial ATP synthase (and glycolysis), cellular ATP:ADP ratios in unstressed cells are maintained at around 10:1. The most important reaction producing and consuming AMP is catalyzed by adenylate kinase $\quad(2 \mathrm{ADP} \leftrightarrow \mathrm{ATP}+\mathrm{AMP})$, a near-equilibrium reaction with an equilibrium constant close to 1 . If the ATP:ADP ratio is 10:1 and the adenylate kinase reaction is at equilibrium, the ATP:AMP ratio would be around 100:1. Although the concentration of AMP rises steeply as the ATP:ADP ratio falls during metabolic stress (Hardie and Hawley 2001), it will usually remain much lower

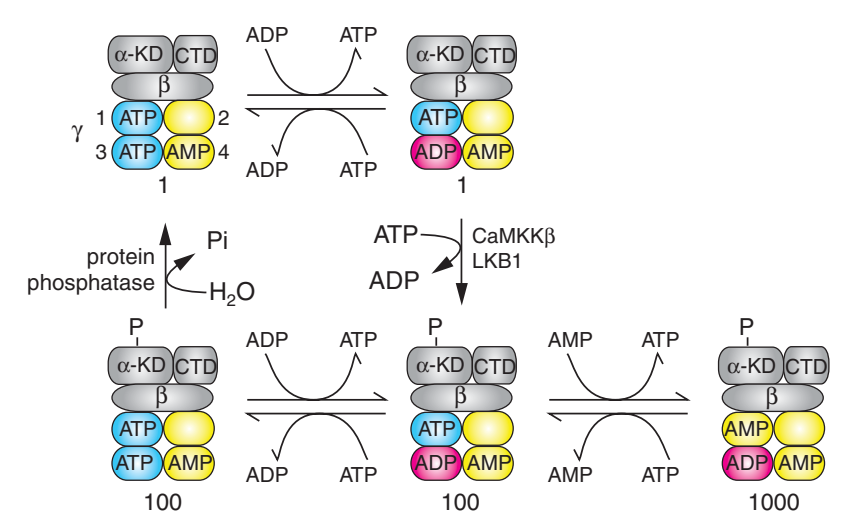

than those of ADP and ATP, and it is therefore difficult to see how it could compete effectively with the other AXPs for binding to the $\gamma$ subunit. However, the concentration of ADP is much closer to that of ATP, so that it could more effectively compete. Moreover, $\mathrm{Mg}-\mathrm{ATP}^{2-}$ has a lower affinity for the $\gamma$ subunit than free ATP (Xiao et al. 2011) and because most cellular ATP is present in the form of the $\mathrm{Mg}$ complex, this further explains how ADP can compete with ATP. These arguments suggest that the AMPK system may normally be monitoring fluctuations in ADP:ATP, with increases in this ratio causing activation by promoting net phosphorylation of Thr172. The effect of AMP to allosterically activate the kinase, which multiplies with the effect of Thr172 phosphorylation to produce $>1000$-fold activation overall, may only come into play during more severe metabolic stresses, when AMP levels might approach those of ADP and free ATP. This regulatory system, while complex (Fig. 2 ), would allow AMPK to respond to energy stress across a broad range of cellular ADP:ATP and AMP:ATP ratios, and with a wide dynamic range of $>1000$-fold activation.

A plausible mechanism to explain how binding of AMP or ADP at site 3 prevents dephosphorylation of Thr172 has been suggested by a new structure in which an almost full-length $\alpha 1$ subunit (including the kinase domain phosphorylated on Thr172) was crystallized in complex with full-length $\gamma 1$ and the $\beta 1-C T D$ (Xiao et al. 2011). As in the original structure that lacked the kinase domain (Xiao et al. 2007), the CTDs of $\alpha$ and $\beta$ associate closely together, but in the new structure they also interact with the activation loop of the kinase domain, hindering access to Thr172 of protein phosphatases that would dephosphorylate the residue. The kinase domain and the $\alpha$-CTD, at opposite ends of the $\alpha$ subunit, are connected by a long extended peptide that wraps around the $\gamma$ subunit, resembling two "arms" with the hands clasped together, holding the $\gamma$ subunit in a tight embrace (Fig. 3, right). The "hands" form a structure known as the $\alpha$ hook, which contacts the exposed phosphate group of AMP bound at site 3. Comparison with a previous partial structure with ATP bound at this site (Xiao et al. 2007) indicates that binding of ATP, but not ADP or AMP, might disrupt the interaction with the $\alpha$ hook. This suggests a model (Xiao et al. 2011) in which binding of ATP at site 3 prevents the association of the

Figure 2. Current model for the regulation of mammalian AMPK by adenine nucleotides. The numbers below the five species refer to their approximate kinase activities relative to the basal state (top left). In the basal state, site 4 is occupied by AMP and sites 1 and 3 by ATP. An increase in the cellular ADP:ATP ratio causes ATP in site 3 to be replaced by ADP (top center). This form is more susceptible to phosphorylation by $\mathrm{LKB} 1$ and $\mathrm{CaMKK} \beta$, converting it to a form (bottom center) that has $>100$-fold higher activity. If the metabolic stress worsens, AMP may rise to levels where it replaces ATP (or ADP) at site 1 (bottom right). This causes a further 10 -fold activation, yielding $>1000$-fold activation overall. The complex remains in the active, phosphorylated form until ADP is replaced by ATP at site 3 (bottom left), because only in this state does dephosphorylation to the basal state occur. 


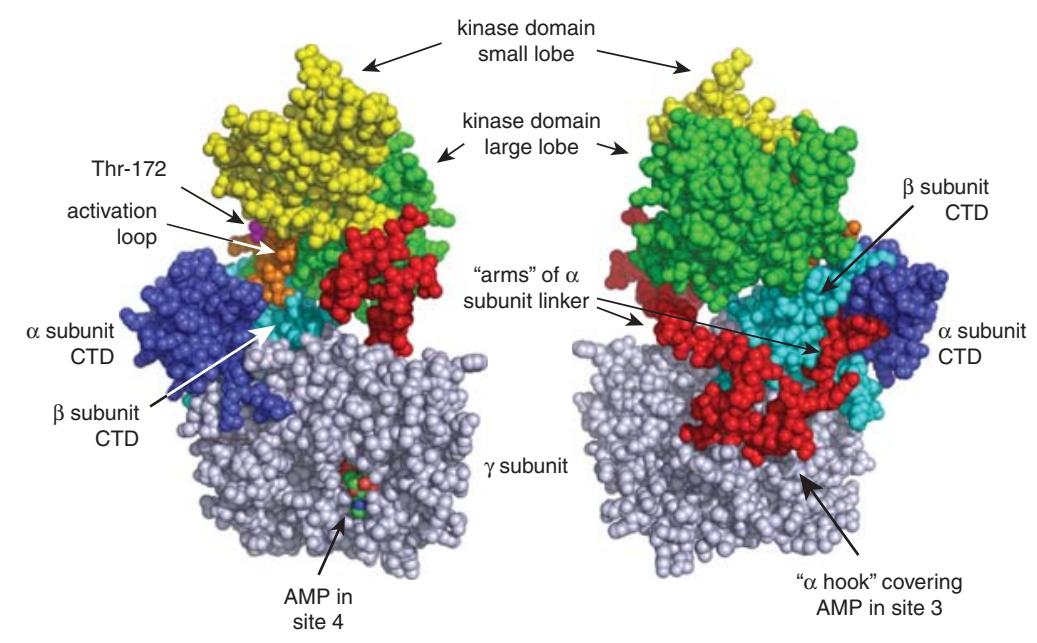

Figure 3. Two views of the crystal structure of an active, phosphorylated form of mammalian AMPK (Xiao et al. 2011). The color coding of domains approximates that in Figure 1, but the construct only contained the CTD of the $\beta$ subunit, with the CBM missing. The flexible loop containing Ser485 had also been deleted, whereas the AID, although present, was not resolved in the crystal structure. The left-hand view shows how the $\alpha$ - and $\beta$-CTDs interact with each other and with the activation loop of the kinase domain (shown in orange), blocking access of protein phosphatases to Thr172 (in lilac). The right-hand view is rotated $160^{\circ}$ about the $y$ axis, and shows the two "arms" of the linker peptide that connect the kinase domain and CTD of the $\alpha$ subunit, with the "hands" (the " $\alpha$ hook") interacting with (and obscuring, in this view) AMP bound at site 3 .

$\alpha$ hook, weakening the tight embrace of the "arms" of the $\alpha$ subunit linker peptide with the $\gamma$ subunit, thus causing the entire kinase domain to swing away from the $\alpha / \beta$ CTDs and exposing Thr172 for dephosphorylation.

Unfortunately, the new structure does not provide obvious explanations for the other two mechanisms by which AMP and/or ADP activate the complex, that is, enhanced phosphorylation of Thr172 (Hawley et al. 1995; Oakhill et al. 2010, 2011) or allosteric activation (Carling et al. 1989). The AID, which was proposed to be involved in allosteric activation (Chen et al. 2009), was not resolved in the structure (although present in the $\alpha$ subunit construct used), suggesting that it was either unstructured or mobile within the crystal (Xiao et al. 2011).

\section{REGULATION OF AMPK BY METABOLIC STRESSES, CYTOKINES, DRUGS, AND XENOBIOTICS}

As expected for a sensor of cellular energy status activated by increases in ADP and/or AMP, AMPK is switched on by stresses that inhibit ATP synthesis (e.g., hypoxia, hypoglycemia), or that accelerate ATP consumption (e.g., exercise/muscle contraction; Hardie 2007). Although AMPK evolved in single-celled eukaryotes and may still be involved in cell-autonomous responses to glucose starvation in multicellular eukaryotes, cytokines that regulate whole-body energy balance in mammals also appear to have acquired the ability to modulate the system. These cytokines include the adipokines leptin (Minokoshi et al. 2002) and adiponectin (Yamauchi et al. 2002), which are secreted by adipocytes and acutely activate AMPK in skeletal muscle, thus stimulating fat oxidation. Regulation of AMPK in the hypothalamus also mediates responses to changes in the plasma levels of several hormones, as well as glucose. Both leptin and the thyroid hormone T3 were reported to inhibit or down-regulate AMPK in the hypothalamus, and this was associated with increased activity of the sympathetic nervous system. This caused increased fat oxidation in skeletal muscle in response to leptin, a response that had a longer time course than the direct effects of the hormone on muscle (Minokoshi et al. 2002), and increased expression of markers of thermogenesis in brown adipose tissue in response to T3 (Lopez et al. 2010). These effects help to explain how these hormones increase energy expenditure and/or heat production. Interestingly, mouse knockouts of AMPK- $\alpha 2$, the isoform particularly down-regulated by leptin in the hypothalamus, have elevated catecholamine levels, consistent with an activation of the sympathetic nervous system (Viollet et al. 2003). It has also been proposed that leptin depresses feeding behavior by inhibiting the $\alpha 2$ isoform of AMPK in the hypothalamus (Minokoshi et al. 2004). Consistent with this, agents that stimulate AMPK in the hypothalamus, including adiponectin, the gut hormone ghrelin, cannabinoids, and the drug 5-aminoimidazole-4-carboxamide riboside, all promote food intake in rodents (Andersson et al. 2004; Kola et al. 2005; Kubota et al. 2007). Surprisingly, conditional knockout of AMPK- $\alpha 2$ in hypothalamic neurones expressing either pro-opiomelanocortin (POMC) or Agouti-related protein (AGRP) did not ablate the increased firing of action potentials when these neurones were treated with leptin (Claret et al. 2007). However, they did lose decreased firing of action potentials in response to glucose removal. This suggests that AMPK$\alpha 2$ may be involved in the hypothalamic response to 
hypoglycemia (Claret et al. 2007). Consistent with this, down-regulation of $\alpha 2$ in the ventromedial hypothalamus of rats, using short hairpin RNAs delivered by viral vectors, resulted in a defective counter-regulatory response to hypoglycemia, that is, a failure to secrete glucagon from the pancreas and epinephrine from the adrenal medulla (McCrimmon et al. 2008). Taken together, these findings suggest that a kinase that evolved to mediate the cell-autonomous response to glucose starvation in singlecelled eukaryotes has retained this function in multicellular organisms. However, it now senses hypoglycemia in the hypothalamus to initiate complex physiological responses, that is, regulation of feeding behavior and hormone secretion.

In most cases, the mechanisms by which AMPK is activated (and inhibited) by cytokines remain unclear. AMPK is also activated by many drugs and xenobiotics, including drugs used clinically in the treatment of type 2 diabetes, such as metformin (Zhou et al. 2001) and thiazolidinediones (Fryer et al. 2002). Other xenobiotics that activate AMPK include plant products that are "nutraceuticals" (e.g., resveratrol present in grapes and red wine [Baur et al. 2006] and epigallocatechin gallate present in green tea [Hwang et al. 2007]), and plant products used in traditional Chinese medicine (e.g., berberine [Lee et al. 2006] and hispidulin [Lin et al. 2010]). Interestingly, metformin was derived from galegine, a natural product of the plant Galega officinalis, which was used in traditional European herbal medicine; galegine is also a potent activator of AMPK (Mooney et al. 2008).

Although some of these AMPK-activating drugs and xenobiotics can be classed as polyphenols, there are no other structural similarities between them, so an obvious question was how they all activate AMPK. Many are secondary plant metabolites, and an interesting possibility was that they are produced by plants to discourage grazing by herbivores or insects, or protect against pathogen infection. One way of achieving this would be for these defense compounds to inhibit mitochondrial ATP synthesis, making them poisonous to grazing animals or pathogens. However, this mechanism would also activate AMPK, a very sensitive indicator of mitochondrial poisoning. In support of this idea, G. officinalis (also known as goat's rue) is poisonous to herbivores and classed as a noxious weed in the United States, while resveratrol is produced by grapes in response to fungal infection. In addition, metformin has been reported to inhibit complex I of the mitochondrial respiratory chain (El-Mir et al. 2000; Owen et al. 2000), and resveratrol to inhibit mitochondrial $\mathrm{F}_{1}$ ATP synthase (Gledhill et al. 2007). To test whether activation of AMPK by these compounds was indeed secondary to inhibition of mitochondrial function, we made use of isogenic HEK-293 cell lines expressing either the wild-type $\gamma 2$ subunit (in which AMPK complexes are sensitive to increases in cellular AMP/ADP), or $\gamma 2$ with a mutation in site 3 (R531G, which renders AMPK complexes insensitive to such increases; Hawley et al. 2010). This allowed us to show that many of these drugs and xenobiotics (e.g., metformin, galegine, thiazolidinediones, phenobarbital, berberine) activate AMPK by inhibiting the respiratory chain, while others (e.g., oligomycin, resveratrol) do so by inhibiting the mitochondrial $\mathrm{F}_{1}$ ATP synthase.

\section{ROLES OF AMPK IN CANCER AND IN VIRAL INFECTION}

The finding that LKB1, a known tumor suppressor, acted upstream of AMPK (Hawley et al. 2003; Woods et al. 2003) provided the first link between AMPK and cancer. AMPK activation causes a p53-dependent cell cycle arrest (Imamura et al. 2001) and inhibits essentially all biosynthetic pathways required for cell growth, including synthesis of fatty acids, phospholipids, proteins, and ribosomal RNA (Hardie 2007; Hoppe et al. 2009). Thus, AMPK activation would be expected to suppress cell growth and proliferation. Consistent with this, it was found that diabetics treated with metformin had a lower incidence of cancer than those on other medications (Evans et al. 2005). This association has been confirmed in several other retrospective studies, including one in which breast cancer patients already taking metformin for diabetes had a significantly better response to chemotherapy than diabetics not on metformin, as well as nondiabetics (Jiralerspong et al. 2009). Metformin, its more potent sister drug phenformin, and A-769662 (a direct AMPK activator developed by Abbott) also significantly delayed the onset of tumors in a tumor-prone mouse model (Huang et al. 2008). Since metformin/ phenformin and A-769662 activate AMPK by distinct mechanisms, the possibility that this delay in tumorigenesis was due to "off-target" (i.e., AMPK-independent) effects seems unlikely. While the AMPK activators used in this latter study did delay tumorigenesis, all of the mice eventually developed tumors. How then do tumor cells eventually escape from the cytostatic effects of AMPK-activating drugs? One explanation may be that they acquire additional mutations that reduce or prevent continued AMPK activation. One such mutation would be loss of LKB1, which has been estimated to occur in up to $30 \%$ of non-small-cell lung cancers (Sanchez-Cespedes et al. 2002; Ji et al. 2007) and 20\% of cervical cancers (Wingo et al. 2009). However, there may be other mechanisms. In one recent study, AMPK activation was found to be down-regulated compared with normal epithelium (based on immunohistochemistry using anti-pT172 antibody) in 318 out of 349 breast cancer biopsies (Hadad et al. 2009). The mechanisms responsible for down-regulation in these cases were not clear, although loss-of-function mutations in LKB1 appear to be rare in breast cancer, suggesting that other mechanisms may operate.

In some respects, viral infection of cells demonstrates analogies to tumorigenesis. In both cases, the biosynthetic machinery of the cell has been usurped by abnormal genes, by viral genes in the former case, and by oncogenic mutations or loss of tumor suppressors in the latter. The effects of viral infection on AMPK were recently studied using an in vitro model system in which a human hepatoma cell line was infected using hepatitis $\mathrm{C}$ 
virus (HCV) (Mankouri et al. 2010). When HCV infects host cells it switches on both protein synthesis (making a single polyprotein that is cleaved into the 10 proteins encoded by the viral RNA genome) and fatty acid/triglyceride synthesis, which are required for the viral lipid envelope. One might expect that the large increase in demand for ATP caused by rapid protein and lipid synthesis would lead to activation of AMPK, but in fact the opposite occurs, in that phosphorylation of Thr172 on AMPK is reduced relative to uninfected controls (Mankouri et al. 2010). The mechanism responsible appears to be that one of the viral proteins (NS5A) binds to and activates phosphatidylinositol (PI) 3-kinase, leading to activation of the phosphatidylinositol trisphosphate $\left(\mathrm{PIP}_{3}\right)$-activated kinase PKB/Akt (Street et al. 2004). $\mathrm{PKB} /$ Akt in turn phosphorylates the $\alpha 1$ subunit of AMPK at a carboxy-terminal site, Ser485 (Mankouri et al. 2010), which has been previously reported to inhibit phosphorylation at Thr172, and consequent activation by LKB1 (Horman et al. 2006). By transfecting DNA encoding a nonphosphorylatable S485A mutant of $\alpha 1$, it was shown that phosphorylation of Ser485 is required for viral replication (Mankouri et al. 2010). Since PKB/Akt is activated in many tumor cells (e.g., owing to mutation in PI 3-kinase or loss of the $\mathrm{PIP}_{3}$ phosphatase, PTEN), this may also be a mechanism by which AMPK is down-regulated in tumor cells, allowing unrestricted biosynthesis without the restraining influence of AMPK. Interestingly, the long-term complications of chronic $\mathrm{HCV}$ infection include increased risk of hepatocellular carcinoma. Since AMPK is cytostatic, the fact that the virus has already down-regulated AMPK may explain this deleterious consequence of chronic infection. It is tempting to speculate that other viruses associated with specific cancers, for example, human papillomavirus in cervical cancer, may also down-regulate AMPK.

\section{CONCLUDING REMARKS}

AMPK is a cellular energy sensor that, once activated by metabolic stresses, maintains energy homeostasis by switching on alternate catabolic pathways while inhibiting energy-consuming anabolic pathways, including cell growth and proliferation. AMPK occurs invariably as heterotrimeric complexes comprising a catalytic $\alpha$ subunit and regulatory $\beta$ and $\gamma$ subunits. AMPK is activated by phosphorylation of Thr172 by LKB1, which is promoted by binding of AMP or ADP to the AMPK- $\gamma$ subunit, and by a further allosteric activation caused by binding of AMP at a different site on the $\gamma$ subunit. Many drugs and xenobiotics activate AMPK, and in most cases these act as metabolic poisons that inhibit mitochondrial ATP synthesis and thus increase cellular ADP:ATP and AMP:ATP ratios. AMPK is likely to mediate most, if not all, of the tumor suppressor effects of LKB1, and the cytostatic effects of AMPK may explain findings that the antidiabetic drug metformin provides protection against the development of cancer. However, whether AMPK activators can be used to treat cancer once it has been diagnosed remains less certain, because many tumor cells appear to have acquired mechanisms to down-regulate AMPK. Viral infection of mammalian cells bears some analogies with tumorigenesis, and down-regulation of AMPK may both be necessary for viral infection and help to explain the promotion of tumors caused by chronic infection with some viruses.

\section{REFERENCES}

Adams J, Chen ZP, Van Denderen BJ, Morton CJ, Parker MW, Witters LA, Stapleton D, Kemp BE. 2004. Intrasteric control of AMPK via the $\gamma-1$ subunit AMP allosteric regulatory site. Protein Sci 13: 155-165.

Alderson A, Sabelli PA, Dickinson JR, Cole D, Richardson M, Kreis M, Shewry PR, Halford NG. 1991. Complementation of snf1, a mutation affecting global regulation of carbon metabolism in yeast, by a plant protein kinase cDNA. Proc Natl Acad Sci 88: 8602-8605.

Amodeo GA, Rudolph MJ, Tong L. 2007. Crystal structure of the heterotrimer core of Saccharomyces cerevisiae AMPK homologue SNF1. Nature 449: 492-495.

Andersson U, Filipsson K, Abbott CR, Woods A, Smith K, Bloom SR, Carling D, Small CJ. 2004. AMP-activated protein kinase plays a role in the control of food intake. $J$ Biol Chem 279: 12005-12008.

Apfeld J, O'Connor G, McDonagh T, Distefano PS, Curtis R. 2004. The AMP-activated protein kinase AAK-2 links energy levels and insulin-like signals to lifespan in C. elegans. Genes Dev 18: 3004-3009.

Aschenbach WG, Suzuki Y, Breeden K, Prats C, Hirshman MF, Dufresne SD, Sakamoto K, Vilardo PG, Steele M, Kim JH, et al. 2001. The muscle-specific protein phosphatase PP1G/ $\mathrm{R}(\mathrm{GL})(\mathrm{G}(\mathrm{M}))$ is essential for activation of glycogen synthase by exercise. J Biol Chem 276: 39959-39967.

Baena-Gonzalez E, Rolland F, Thevelein JM, Sheen J. 2007. A central integrator of transcription networks in plant stress and energy signalling. Nature 448: 938-942.

Bateman A. 1997. The structure of a domain common to archaebacteria and the homocystinuria disease protein. Trends Biochem Sci 22: 12-13.

Baur JA, Pearson KJ, Price NL, Jamieson HA, Lerin C, Kalra A, Prabhu VV, Allard JS, Lopez-Lluch G, Lewis K, et al. 2006. Resveratrol improves health and survival of mice on a highcalorie diet. Nature 444: 337-342.

Beg ZH, Allmann DW, Gibson DM. 1973. Modulation of 3-hydroxy-3-methylglutaryl coenzyme: A reductase activity with cAMP and with protein fractions of rat liver cytosol. Biochem Biophys Res Comm 54: 1362-1369.

Bendayan M, Londono I, Kemp BE, Hardie GD, Ruderman N, Prentki M. 2009. Association of AMP-activated protein kinase subunits with glycogen particles as revealed in situ by immunoelectron microscopy. J Histochem Cytochem 57: 963-971.

Blair E, Redwood C, Ashrafian H, Oliveira M, Broxholme J, Kerr B, Salmon A, Ostman-Smith I, Watkins H. 2001. Mutations in the $\gamma$-2 subunit of AMP-activated protein kinase cause familial hypertrophic cardiomyopathy: Evidence for the central role of energy compromise in disease pathogenesis. Hum Mol Genet 10: 1215-1220.

Carling D, Hardie DG. 1989. The substrate and sequence specificity of the AMP-activated protein kinase. Phosphorylation of glycogen synthase and phosphorylase kinase. Biochim Biophys Acta 1012: 81-86.

Carling D, Zammit VA, Hardie DG. 1987. A common bicyclic protein kinase cascade inactivates the regulatory enzymes of fatty acid and cholesterol biosynthesis. FEBS Lett 223: 217-222.

Carling D, Clarke PR, Zammit VA, Hardie DG. 1989. Purification and characterization of the AMP-activated protein kinase. 
Copurification of acetyl-CoA carboxylase kinase and 3-hydroxy-3-methylglutaryl-CoA reductase kinase activities. Eur J Biochem 186: 129-136.

Carlson CA, Kim KH. 1973. Regulation of hepatic acetyl coenzyme A carboxylase by phosphorylation and dephosphorylation. J Biol Chem 248: 378-380.

Chen L, Jiao ZH, Zheng LS, Zhang YY, Xie ST, Wang ZX, Wu JW. 2009. Structural insight into the autoinhibition mechanism of AMP-activated protein kinase. Nature 459: 11461149.

Cheung PCF, Salt IP, Davies SP, Hardie DG, Carling D. 2000. Characterization of AMP-activated protein kinase $\gamma$ subunit isoforms and their role in AMP binding. Biochem $J$ 346: 659-669.

Claret M, Smith MA, Batterham RL, Selman C, Choudhury AI, Fryer LG, Clements M, Al-Qassab H, Heffron H, Xu AW, et al. 2007. AMPK is essential for energy homeostasis regulation and glucose sensing by POMC and AgRP neurons. J Clin Invest 117: 2325-2336.

Crute BE, Seefeld K, Gamble J, Kemp BE, Witters LA. 1998. Functional domains of the $\alpha 1$ catalytic subunit of the AMP-activated protein kinase. J Biol Chem 273: $35347-$ 35354.

Daniel TD, Carling D. 2002. Functional analysis of mutations in the $\gamma 2$ subunit of AMP-activated protein kinase associated with cardiac hypertrophy and Wolff-Parkinson-White syndrome. J Biol Chem 277: 51017-51024.

Davies SP, Helps NR, Cohen PTW, Hardie DG. 1995. 5'-AMP inhibits dephosphorylation, as well as promoting phosphorylation, of the AMP-activated protein kinase. Studies using bacterially expressed human protein phosphatase-2C $\alpha$ and native bovine protein phosphatase-2 $\mathrm{A}_{\mathrm{C}}$. FEBS Lett 377: 421-425.

El-Mir MY, Nogueira V, Fontaine E, Averet N, Rigoulet M, Leverve X. 2000. Dimethylbiguanide inhibits cell respiration via an indirect effect targeted on the respiratory chain complex I. J Biol Chem 275: 223-228.

Estruch F, Treitel MA, Yang X, Carlson M. 1992. N-terminal mutations modulate yeast SNF1 protein kinase function. Genetics 132: 639-650.

Evans JM, Donnelly LA, Emslie-Smith AM, Alessi DR, Morris AD. 2005. Metformin and reduced risk of cancer in diabetic patients. BMJ 330: 1304-1305.

Ferrer A, Caelles C, Massot N, Hegardt FG. 1985. Activation of rat liver cytosolic 3-hydroxy-3-methylglutaryl Coenzyme A reductase kinase by adenosine $5^{\prime}$-monophosphate. Biochem Biophys Res Comm 132: 497-504.

Fogarty S, Hawley SA, Green KA, Saner N, Mustard KJ, Hardie DG. 2010. Calmodulin-dependent protein kinase kinase$\beta$ activates AMPK without forming a stable complexSynergistic effects of $\mathrm{Ca}^{2+}$ and AMP. Biochem J 426: 109118.

Fryer LG, Parbu-Patel A, Carling D. 2002. The anti-diabetic drugs rosiglitazone and metformin stimulate AMP-activated protein kinase through distinct pathways. J Biol Chem 277: $25226-25232$.

Gledhill JR, Montgomery MG, Leslie AG, Walker JE. 2007. Mechanism of inhibition of bovine F1-ATPase by resveratrol and related polyphenols. Proc Natl Acad Sci 104: $13632-13637$.

Gollob MH, Green MS, Tang AS, Gollob T, Karibe A, Ali Hassan AS, Ahmad F, Lozado R, Shah G, Fananapazir L, et al. 2001. Identification of a gene responsible for familial Wolff-Parkinson-White syndrome. New Engl J Med 344: $1823-1831$.

Goransson O, McBride A, Hawley SA, Ross FA, Shpiro N, Foretz M, Viollet B, Hardie DG, Sakamoto K. 2007. Mechanism of action of A-769662, a valuable tool for activation of AMP-activated protein kinase. J Biol Chem 282: 3254932560.

Greer EL, Brunet A. 2009. Different dietary restriction regimens extend lifespan by both independent and overlapping genetic pathways in C. elegans. Aging Cell 8: 113-127.
Greer EL, Dowlatshahi D, Banko MR, Villen J, Hoang K, Blanchard D, Gygi SP, Brunet A. 2007. An AMPK-FOXO pathway mediates longevity induced by a novel method of dietary restriction in C. elegans. Curr Biol 17: 1646-1656.

Hadad SM, Baker L, Quinlan PR, Robertson KE, Bray SE, Thomson G, Kellock D, Jordan LB, Purdie CA, Hardie DG, et al. 2009. Histological evaluation of AMPK signalling in primary breast cancer. BMC Cancer 9: 307 .

Hardie DG. 2007. AMP-activated/SNF1 protein kinases: Conserved guardians of cellular energy. Nat Rev Mol Cell Biol 8: $774-785$.

Hardie DG, Hawley SA. 2001. AMP-activated protein kinase: The energy charge hypothesis revisited. BioEssays 23: $1112-1119$.

Hardie DG, Carling D, Sim ATR. 1989. The AMP-activated protein kinase - A multisubstrate regulator of lipid metabolism. Trends Biochem Sci 14: 20-23.

Hardie DG, Carling D, Carlson M. 1998. The AMP-activated/ SNF1 protein kinase subfamily: Metabolic sensors of the eukaryotic cell? Ann Rev Biochem 67: 821-855.

Hawley SA, Selbert MA, Goldstein EG, Edelman AM, Carling D, Hardie DG. 1995. 5'-AMP activates the AMP-activated protein kinase cascade, and $\mathrm{Ca}^{2+} /$ calmodulin the calmodulin-dependent protein kinase I cascade, via three independent mechanisms. J Biol Chem 270: 27186-27191.

Hawley SA, Davison M, Woods A, Davies SP, Beri RK, Carling D, Hardie DG. 1996. Characterization of the AMP-activated protein kinase kinase from rat liver, and identification of threonine-172 as the major site at which it phosphorylates and activates AMP-activated protein kinase. J Biol Chem 271: $27879-27887$.

Hawley SA, Boudeau J, Reid JL, Mustard KJ, Udd L, Makela TP, Alessi DR, Hardie DG. 2003. Complexes between the LKB1 tumor suppressor, STRAD $\alpha / \beta$ and $\mathrm{MO} 25 \alpha / \beta$ are upstream kinases in the AMP-activated protein kinase cascade. J Biol 2: 28.

Hawley SA, Pan DA, Mustard KJ, Ross L, Bain J, Edelman AM, Frenguelli BG, Hardie DG. 2005. Calmodulin-dependent protein kinase kinase- $\beta$ is an alternative upstream kinase for AMP-activated protein kinase. Cell Metab 2: 9-19.

Hawley SA, Ross FA, Chevtzoff C, Green KA, Evans A, Fogarty S, Towler MC, Brown LJ, Ogunbayo OA, Evans AM, et al. 2010. Use of cells expressing $\gamma$ subunit variants to identify diverse mechanisms of AMPK activation. Cell Metab 11: $554-565$.

Hedbacker K, Carlson M. 2008. SNF1/AMPK pathways in yeast. Front Biosci 13: 2408-2420.

Hemminki A, Markie D, Tomlinson I, Avizienyte E, Roth S, Loukola A, Bignell G, Warren W, Aminoff M, Hoglund P, et al. 1998. A serine/threonine kinase gene defective in Peutz-Jeghers syndrome. Nature 391: 184-187.

Hong SP, Leiper FC, Woods A, Carling D, Carlson M. 2003. Activation of yeast Snfl and mammalian AMP-activated protein kinase by upstream kinases. Proc Natl Acad Sci 100: 8839-8843.

Honigberg SM, Lee RH. 1998. Snf1 kinase connects nutritional pathways controlling meiosis in Saccharomyces cerevisiae. Mol Cell Biol 18: 4548-4555.

Hoppe S, Bierhoff H, Cado I, Weber A, Tiebe M, Grummt I, Voit R. 2009. AMP-activated protein kinase adapts rRNA synthesis to cellular energy supply. Proc Natl Acad Sci 106: $17781-17786$.

Horman S, Vertommen D, Heath R, Neumann D, Mouton V, Woods A, Schlattner U, Wallimann T, Carling D, Hue L, et al. 2006. Insulin antagonizes ischemia-induced Thr172 phosphorylation of AMP-activated protein kinase $\alpha$-subunits in heart via hierarchical phosphorylation of Ser485/491. $J$ Biol Chem 281: 5335-5340.

Huang X, Wullschleger S, Shpiro N, McGuire VA, Sakamoto K, Woods YL, McBurnie W, Fleming S, Alessi DR. 2008. Important role of the LKB1-AMPK pathway in suppressing tumorigenesis in PTEN-deficient mice. Biochem $J$ 412: 211-221. 
Hudson ER, Pan DA, James J, Lucocq JM, Hawley SA, Green KA, Baba O, Terashima T, Hardie DG. 2003. A novel domain in AMP-activated protein kinase causes glycogen storage bodies similar to those seen in hereditary cardiac arrhythmias. Current Biol 13: 861-866.

Hurley RL, Anderson KA, Franzone JM, Kemp BE, Means AR, Witters LA. 2005. The $\mathrm{Ca}^{2+} /$ calmoldulin-dependent protein kinase kinases are AMP-activated protein kinase kinases. J Biol Chem 280: 29060-29066.

Hwang JT, Ha J, Park IJ, Lee SK, Baik HW, Kim YM, Park OJ. 2007. Apoptotic effect of EGCG in HT-29 colon cancer cells via AMPK signal pathway. Cancer Lett 247: 115-121.

Imamura K, Ogura T, Kishimoto A, Kaminishi M, Esumi H. 2001. Cell cycle regulation via p53 phosphorylation by a $5^{\prime}$ AMP activated protein kinase activator, 5-aminoimidazole4-carboxamide-1- $\beta$-D-ribofuranoside, in a human hepatocellular carcinoma cell line. Biochem Biophys Res Commun 287: $562-567$.

Ingebritsen TS, Lee H, Parker RA, Gibson DM. 1978. Reversible modulation of the activities of both liver microsomal hydroxymethylglutaryl coenzyme A reductase and its inactivating enzyme. Evidence for regulation by phosphorylationdephosphorylation. Biochem Biophys Res Commun 81: $1268-1277$.

Ji H, Ramsey MR, Hayes DN, Fan C, McNamara K, Kozlowski P, Torrice C, Wu MC, Shimamura T, Perera SA, et al. 2007. LKB1 modulates lung cancer differentiation and metastasis. Nature 448: 807-810.

Jiralerspong S, Palla SL, Giordano SH, Meric-Bernstam F, Liedtke C, Barnett CM, Hsu L, Hung MC, Hortobagyi GN, Gonzalez-Angulo AM. 2009. Metformin and pathologic complete responses to neoadjuvant chemotherapy in diabetic patients with breast cancer. J Clin Oncol 27: $3297-$ 3302.

Jorgensen SB, Nielsen JN, Birk JB, Olsen GS, Viollet B, Andreelli F, Schjerling P, Vaulont S, Hardie DG, Hansen $\mathrm{BF}$, et al. 2004. The $\alpha 2-5^{\prime} \mathrm{AMP}-$ activated protein kinase is a site 2 glycogen synthase kinase in skeletal muscle and is responsive to glucose loading. Diabetes 53: 3074-3081.

Kemp BE. 2004. Bateman domains and adenosine derivatives form a binding contract. J Clin Invest 113: 182-184.

Kemp BE, Oakhill JS, Scott JW. 2007. AMPK structure and regulation from three angles. Structure 15: 1161-1163.

Kola B, Hubina E, Tucci SA, Kirkham TC, Garcia EA, Mitchell SE, Williams LM, Hawley SA, Hardie DG, Grossman AB, et al. 2005. Cannabinoids and ghrelin have both central and peripheral metabolic and cardiac effects via AMP-activated protein kinase. J Biol Chem 280: 25196-25201

Kubota N, Yano W, Kubota T, Yamauchi T, Itoh S, Kumagai H, Kozono H, Takamoto I, Okamoto S, Shiuchi T, et al. 2007. Adiponectin stimulates AMP-activated protein kinase in the hypothalamus and increases food intake. Cell Metab 6: $55-68$.

Lee YS, Kim WS, Kim KH, Yoon MJ, Cho HJ, Shen Y, Ye JM, Lee CH, Oh WK, Kim CT, et al. 2006. Berberine, a natural plant product, activates AMP-activated protein kinase with beneficial metabolic effects in diabetic and insulin-resistant states. Diabetes 55: 2256-2264.

Lin YC, Hung CM, Tsai JC, Lee JC, Chen YL, Wei CW, Kao JY, Way TD. 2010. Hispidulin potently inhibits human glioblastoma multiforme cells through activation of AMPactivated protein kinase (AMPK). J Agric Food Chem 58: 9511-9517.

Lizcano JM, Göransson O, Toth R, Deak M, Morrice NA, Boudeau J, Hawley SA, Udd L, Mäkelä TP, Hardie DG, et al. 2004. LKB1 is a master kinase that activates 13 protein kinases of the AMPK subfamily, including the MARK/ PAR-1 kinases. EMBO J 23: 833-843.

Lopez M, Varela L, Vazquez MJ, Rodriguez-Cuenca S, Gonzalez CR, Velagapudi VR, Morgan DA, Schoenmakers E, Agassandian K, Lage R, et al. 2010. Hypothalamic AMPK and fatty acid metabolism mediate thyroid regulation of energy balance. Nat Med 16: 1001-1008.
Machovic M, Janecek Sh. 2006. The evolution of putative starch-binding domains. FEBS Lett 580: 6349-6356.

Mackintosh RW, Davies SP, Clarke PR, Weekes J, Gillespie JG, Gibb BJ, Hardie DG. 1992. Evidence for a protein kinase cascade in higher plants. 3-Hydroxy-3-methylglutaryl-CoA reductase kinase. Eur J Biochem 209: 923-931.

Mankouri J, Tedbury PR, Gretton S, Hughes ME, Griffin SD, Dallas ML, Green KA, Hardie DG, Peers C, Harris M. 2010. Enhanced hepatitis $C$ virus genome replication and lipid accumulation mediated by inhibition of AMP-activated protein kinase. Proc Natl Acad Sci 107: 11549-11554.

McBride A, Ghilagaber S, Nikolaev A, Hardie DG. 2009. The glycogen-binding domain on AMP-activated protein kinase is a regulatory domain that allows the kinase to act as a sensor of glycogen structure. Cell Metab 9: 23-34.

McCrimmon RJ, Shaw M, Fan X, Cheng H, Ding Y, Vella MC, Zhou L, McNay EC, Sherwin RS. 2008. Key role for AMP-activated protein kinase in the ventromedial hypothalamus in regulating counterregulatory hormone responses to acute hypoglycemia. Diabetes 57: 444-450.

Minokoshi Y, Kim YB, Peroni OD, Fryer LG, Muller C, Carling D, Kahn BB. 2002. Leptin stimulates fatty-acid oxidation by activating AMP-activated protein kinase. Nature 415: $339-343$

Minokoshi Y, Alquier T, Furukawa N, Kim YB, Lee A, Xue B, Mu J, Foufelle F, Ferre P, Birnbaum MJ, et al. 2004. AMP-kinase regulates food intake by responding to hormonal and nutrient signals in the hypothalamus. Nature 428: $569-574$

Mooney MH, Fogarty S, Stevenson C, Gallagher AM, Palit P, Hawley SA, Hardie DG, Coxon GD, Waigh RD, Tate RJ, et al. 2008. Mechanisms underlying the metabolic actions of galegine that contribute to weight loss in mice. $\mathrm{Br} \mathrm{J} \mathrm{Phar-}$ macol 153: $1669-1677$

Moore F, Weekes J, Hardie DG. 1991. AMP triggers phosphorylation as well as direct allosteric activation of rat liver AMP-activated protein kinase. A sensitive mechanism to protect the cell against ATP depletion. Eur J Biochem 199: 691-697.

Munday MR, Campbell DG, Carling D, Hardie DG. 1988. Identification by amino acid sequencing of three major regulatory phosphorylation sites on rat acetyl-CoA carboxylase. Eur $J$ Biochem 175: $331-338$.

Narbonne P, Roy R. 2006. Inhibition of germline proliferation during $C$. elegans Dauer development requires PTEN, LKB1 and AMPK signalling. Development 133: 611-619.

Narbonne P, Roy R. 2009. Caenorhabditis elegans Dauers need LKB1/AMPK to ration lipid reserves and ensure long-term survival. Nature 457: 210-214.

Oakhill JS, Chen ZP, Scott JW, Steel R, Castelli LA, Ling N, Macaulay SL, Kemp BE. 2010. $\beta$-Subunit myristoylation is the gatekeeper for initiating metabolic stress sensing by AMP-activated protein kinase (AMPK). Proc Natl Acad Sci 107: $19237-19241$.

Oakhill JS, Steel R, Chen ZP, Scott JW, Ling N, Tam S, Kemp BE. 2011. AMPK is a direct adenylate charge regulated protein kinase. Science 332: 1433-1435.

Owen MR, Doran E, Halestrap AP. 2000. Evidence that metformin exerts its anti-diabetic effects through inhibition of complex 1 of the mitochondrial respiratory chain. Biochem J 348: 607-614.

Pang T, Xiong B, Li JY, Qiu BY, Jin GZ, Shen JK, Li J. 2007. Conserved $\alpha$-helix acts as autoinhibitory sequence in AMP-activated protein kinase $\alpha$ subunits. $J$ Biol Chem 282: 495-506.

Polekhina G, Gupta A, Michell BJ, van Denderen B, Murthy S, Feil SC, Jennings IG, Campbell DJ, Witters LA, Parker MW, et al. 2003. AMPK $\beta$-Subunit targets metabolic stress-sensing to glycogen. Current Biol 13: 867-871.

Sanchez-Cespedes M, Parrella P, Esteller M, Nomoto S, Trink B, Engles JM, Westra WH, Herman JG, Sidransky D. 2002. Inactivation of LKB1/STK11 is a common event in adenocarcinomas of the lung. Cancer Res 62: 3659-3662. 
Sanders MJ, Grondin PO, Hegarty BD, Snowden MA, Carling D. 2007. Investigating the mechanism for AMP activation of the AMP-activated protein kinase cascade. Biochem $J$ 403: $139-148$.

Schmidt MC, McCartney RR. 2000. $\beta$-Subunits of Snf1 kinase are required for kinase function and substrate definition. EMBO J 19: 4936-4943.

Scott JW, Hawley SA, Green KA, Anis M, Stewart G, Scullion GA, Norman DG, Hardie DG. 2004. CBS domains form energy-sensing modules whose binding of adenosine ligands is disrupted by disease mutations. J Clin Invest 113: 274-284.

Stahmann N, Woods A, Carling D, Heller R. 2006. Thrombin activates AMP-activated protein kinase in endothelial cells via a pathway involving $\mathrm{Ca}^{2+} /$ calmodulin-dependent protein kinase kinase $\beta$. Mol Cell Biol 26: 5933-5945.

Stein SC, Woods A, Jones NA, Davison MD, Carling D. 2000. The regulation of AMP-activated protein kinase by phosphorylation. Biochem J 345: 437-443.

Street A, Macdonald A, Crowder K, Harris M. 2004. The Hepatitis C virus NS5A protein activates a phosphoinositide 3-kinase-dependent survival signaling cascade. J Biol Chem 279: $12232-12241$.

Suter M, Riek U, Tuerk R, Schlattner U, Wallimann T, Neumann D. 2006. Dissecting the role of $5^{\prime}$-AMP for allosteric stimulation, activation, and deactivation of AMP-activated protein kinase. J Biol Chem 281: 32207-32216.

Sutherland CM, Hawley SA, McCartney RR, Leech A, Stark MJ, Schmidt MC, Hardie DG. 2003. Elm1p is one of three upstream kinases for the Saccharomyces cerevisiae SNF1 complex. Curr Biol 13: 1299-1305.

Tamas P, Hawley SA, Clarke RG, Mustard KJ, Green K, Hardie DG, Cantrell DA. 2006. Regulation of the energy sensor AMP-activated protein kinase by antigen receptor and $\mathrm{Ca}^{2+}$ in T lymphocytes. J Exp Med 203: 1665-1670.

Thelander M, Olsson T, Ronne H. 2004. Snf1-related protein kinase 1 is needed for growth in a normal day-night light cycle. EMBO J 23: 1900-1910.

Townley R, Shapiro L. 2007. Crystal structures of the adenylate sensor from fission yeast AMP-activated protein kinase. Science 315: 1726-1729.

Vernia S, Solaz-Fuster MC, Gimeno-Alcaniz JV, Rubio T, Garcia-Haro L, Foretz M, de Cordoba SR, Sanz P. 2009. AMP-activated protein kinase phosphorylates R5/PTG, the glycogen targeting subunit of the R5/PTG-protein phosphatase 1 holoenzyme, and accelerates its downregulation by the laforin-malin complex. J Biol Chem 284: $8247-8255$

Viollet B, Andreelli F, Jorgensen SB, Perrin C, Geloen A, Flamez D, Mu J, Lenzner C, Baud O, Bennoun M, et al. 2003. The AMP-activated protein kinase $\alpha 2$ catalytic subunit controls whole-body insulin sensitivity. J Clin Invest 111: 91-98.

Winder WW, Hardie DG. 1996. Inactivation of acetyl-CoA carboxylase and activation of AMP-activated protein kinase in muscle during exercise. Am J Physiol 270: E299-E304.

Wingo SN, Gallardo TD, Akbay EA, Liang MC, Contreras CM, Boren T, Shimamura T, Miller DS, Sharpless NE, Bardeesy N, et al. 2009. Somatic LKB1 mutations promote cervical cancer progression. PLOS ONE 4: e5137.

Woods A, Johnstone SR, Dickerson K, Leiper FC, Fryer LG, Neumann D, Schlattner U, Wallimann T, Carlson M, Carling D. 2003. LKB1 is the upstream kinase in the AMP-activated protein kinase cascade. Curr Biol 13: 2004-2008.

Woods A, Dickerson K, Heath R, Hong SP, Momcilovic M, Johnstone SR, Carlson M, Carling D. $2005 . \mathrm{Ca}^{2+} /$ calmodulin-dependent protein kinase kinase- $\beta$ acts upstream of AMP-activated protein kinase in mammalian cells. Cell Metab 2: 21-33.

Xiao B, Heath R, Saiu P, Leiper FC, Leone P, Jing C, Walker PA, Haire L, Eccleston JF, Davis CT, et al. 2007. Structural basis for AMP binding to mammalian AMP-activated protein kinase. Nature 449: 496-500.

Xiao B, Sanders MJ, Underwood E, Heath R, Mayer FV, Carmena D, Jing C, Walker PA, Eccleston JF, Haire LF, et al. 2011. Structure of mammalian AMPK and its regulation by ADP. Nature 472: 230-233.

Yamauchi T, Kamon J, Minokoshi Y, Ito Y, Waki H, Uchida S, Yamashita S, Noda M, Kita S, Ueki K, et al. 2002. Adiponectin stimulates glucose utilization and fatty-acid oxidation by activating AMP-activated protein kinase. Nat Med 6: $1288-1295$.

Yeh LA, Lee KH, Kim KH. 1980. Regulation of rat liver acetylCoA carboxylase. Regulation of phosphorylation and inactivation of acetyl-CoA carboxylase by the adenylate energy charge. J Biol Chem 255: 2308-2314.

Zhou G, Myers R, Li Y, Chen Y, Shen X, Fenyk-Melody J, Wu M, Ventre J, Doebber T, Fujii N, et al. 2001. Role of AMP-activated protein kinase in mechanism of metformin action. J Clin Invest 108: 1167-1174. 


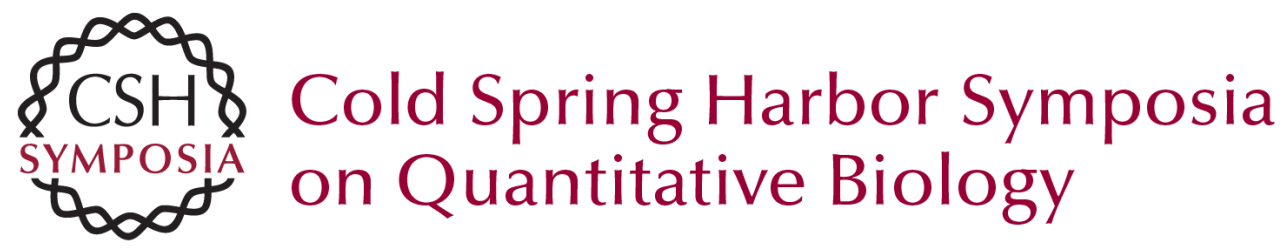

\section{Adenosine Monophosphate-Activated Protein Kinase: A Central Regulator of Metabolism with Roles in Diabetes, Cancer, and Viral Infection}

D.G. Hardie

Cold Spring Harb Symp Quant Biol 2011 76: 155-164 originally published online November 9, 2011

Access the most recent version at doi:10.1101/sqb.2011.76.010819

References This article cites 106 articles, 46 of which can be accessed free at: http://symposium.cshlp.org/content/76/155.full.html\#ref-list-1

License

Email Alerting Receive free email alerts when new articles cite this article - sign up in Service the box at the top right corner of the article or click here. 